With breast cancer, operation is generally successful in early cases, but when the axilla is involved, much less so. For the latter, radium therapy has been extensively tried with questionable success, and $\mathrm{X}$-rays are probably a more suitable agent. In uterine cancer, frankly operable cases are treated as successfully by radium as by surgery, but with a smaller operation mortality, and surgically inoperable cases treated by radiation yield a by no means negligible percentage of clinical cures. Certain nonmalignant conditions also respond well to radium treatment, for example, uterine hæmorrhage. Several important experimental researches are also included in the report.

Ir is estimated that the total quantity of radium available for treatment in Great Britain is now about $70 \mathrm{gm}$. Of this amount, the Radium Commission controls $23 \mathrm{gm}$., which includes $20 \mathrm{gm}$. placed at its disposal by the Radium Trust, and three $1 \mathrm{gm}$. units, the property of the King Edward's Hospital Fund (Fifth Annual Reports of the National Radium Trust and Radium Commission 1933-1934. H.M. Stationery Office. $9 d$.net). The radium is distributed for use for experimental work and treatment between the Medical Research Council and the National Physical Laboratory, certain London hospitals and institutions, and thirteen national radium centres and five regional radium centres. In addition, allocations have been made by certain organisations, such as the British Empire Cancer Campaign, and a considerable amount of radium is privately owned.

\section{National Medical Statistics}

THE Registrar-General's Statistical Review of England and Wales for the Year 1933 (Tables, Part 1: Medical), pp. iv +406 , has recently been published (London : H.M. Stationery Office. 6s. net). It appears that the number of births registered in 1933 was 580,413 , giving a rate of $14 \cdot 4$ per 1,000 persons living. This rate is 0.9 below that for 1932 , and constitutes a new low record. The death-rate was $12 \cdot 3$ per 1,000 persons living, $0 \cdot 3$ above the rate for 1932 (the same as that for 1931) but 0.9 above that for 1930. The deaths of children under one year of age numbered 64 per 1,000 live births against 65 in 1932, 66 in 1931 and 60 in 1930. Cancer showed a death-rate of 1,526 per million persons living against 1,510 in 1932 . If, however, allowance is made for differences in the age constitution of the population, the comparative mortality from cancer shows a slight decrease. Tuberculosis again furnished a new low record of 824 per million living. Puerperal sepsis caused the deaths of 1.75 women per 1,000 live and still births, 0.20 more than the rate for 1932 but 0.09 less than 1930 . The death rate from suicide was 140 per million persons living, a decrease of 3 per million on the record high rate of 1932 . A slow increase in this rate had been continuous for a number of years. Road accidents due to mechanical vehicles were responsible for 5,934 deaths. The figures for the last five years were $5,196,5,752,6,342$, 5,892 and 5,671 respectively.

\section{Exhibition of Microscopes}

The second annual exhibition of microscopes and appliances, conducted by Messrs. W. Watson and Sons, Ltd., 313 High Holborn, London, W.C., which has been open all this week at the Central Hall, Westminster, attracted numerous visitors. A number of mounted specimens were shown on a series of microscopes ranged round the Hall, comprising diatoms, pollens, histological and pathological specimens, and crystals with polarised light. Members of the Quekett Microscopical Club arranged an interesting exhibit of living pond-life, including some beautiful specimens of Volvox and Vorticella. The use and value of the microscope in industry were demonstrated by exhibits illustrating the differences in microscopic structure of various qualities of leather, the size of sugar crystals, cocoa particles and entangled air bubbles as influencing the quality of sweets in confectionery, and the microscopic flora in cheese and in vinegar fermentation. A side-show of considerable interest was a demonstration of the making of the glass discs and their shaping, grinding and polishing so as to form the constituent lenses for microscope objectives. Other exhibits illustrated the detection of forgery and of crime weapons, and formed the subjects of two of the lantern lectures, by Mr. T. J. Ward and Major G. Burrard respectively, which have been a feature of the exhibition. Other lantern lectures included "A Naturalist on the Amazon" (Mr. Robins), "An Amateur among the Stars" (Mr. Offord), and "How Lenses are Made" (Mr. Watson Baker), together with several einematograph displays by the Kodak Company.

\section{Sound and Noise}

A Research and Development Lecture on "Sound and Noise" was given at the Royal Institution on December 12, under the auspices of the Institution and the British Science Guild, by Dr. G. W. C. Kaye, Superintendent of the Physics Department at the National Physical Laboratory. Mr. Hore Belisha, the Minister of Transport, was in the chair. Man has developed very many and ingenious ways of making sounds and noises. In some everyday events the noise is only a small by-product; for example, only about a thousandth part of the energy of a dropped weight or of a hand-clap appears in the form of noise. This figure was increased to a few per cent in the case of motor horns and loud speakers, and even up to 30 per cent or more for the loud speakers used for talking pictures. By comparison with many sounds, the human voice is very weak, and even during shouting the output was only about 0.001 watt. Suitably equipped, an orchestra of 75 has a normal acoustic output of about 0.5 watt, which in strident passages may be increased 100-fold-quite enough, if it could be so applied, to light an average electric lamp.

For the purposes of the measurement of the loudness of noise, a reference standard of sound has been chosen, which consists of a pure note of a frequency of 1,000 cycles per second. The adjustable 